\title{
Auger Electron Spectroscopy of Kernite: Coaxing Useful Information Out of a Recalcitrant Specimen
}

\author{
Douglas C. Meier ${ }^{*}$, Jeffrey Davis ${ }^{*}$, and Edward P. Vicenzi ${ }^{*, * *}$
}

* National Institute of Standard and Technology (NIST), Chemical Sciences and Technology Laboratory, Surface and Microanalysis Science Division, 100 Bureau Dr. MS8371, Gaithersburg, MD 20899-8371

** Smithsonian Institution, Museum Conservation Institute, Suitland, MD 20746

dmeier@nist.gov

Kernite $\left(\mathrm{Na}_{2} \mathrm{~B}_{4} \mathrm{O}_{7} \cdot 4 \mathrm{H}_{2} \mathrm{O}\right)$ is one of the primary commercial mineral sources of boron. Boron is used as a dopant in semiconductors, and its oxides are used in detergents and glass [1]. A sample of this mineral was obtained from Boron, CA. Electron beam microanalysis was performed on it in order to determine the structure and composition of the mineral on the microscale. In particular, the identity and location of possible impurities within the mineral were sought using both x-ray spectroscopy (EDS and WDS) and the more surface-specific Auger electron spectroscopy (AES). The challenges endemic to electron-beam analysis of fragile, insulating, oxygen-rich hydrated minerals, particularly their impact on the AES results, is a primary focus of the current study.

Kernite was readily imaged in VP-SEM mode [2]. It features islands of an amorphous surface film that is distinct from the bulk crystalline structure (Fig. 1). Upon transfer of the specimens to the ultrahigh vacuum (UHV) environment of the scanning Auger microprobe, the friable, columnar, colorless mineral undergoes an accelerated efflorescence that transforms it into an extremely fragile opaque-white material (Fig. 2). Under these vacuum conditions, surface charging became apparent during imaging. The already-fragile structure of the mineral was further weakened upon incidence of the electron beam. The analysis of the Auger spectra of these as-received specimens was meaningless due to the spurious features and electron energy shifts caused by the beam charging effects.

Two methods were used to combat these charging effects. The first involved mounting a $300 \mu \mathrm{m}$ copper aperture in contact with the neat polished crystal (Fig. 3). While charging was reduced significantly for purposes of imaging, argon ion-beam milling to remove adventitious surface carbon resulted in surfaces that still became charged under the probe, reducing the analytical value of the Auger spectra. However, approaching the edge of the aperture eliminated the charging issues, resulting in spectra (Fig. 4, blue) that showed the mineral to be a pure compound of boron and oxygen $(\mathrm{B}: \mathrm{O} \sim 3: 2)$. Redeposited copper from the argon-ion milling process also appears in the spectra, obscuring the spectral position where one would expect to find sodium $(990 \mathrm{eV})$. In an effort to eliminate this problem, kernite was coated with a thin layer of carbon. The argon ion beam was used to drill a hole through this surface layer; AES was then performed on the mineral underneath while under a low-energy argon-ion neutralization flood. These results (Fig. 4, red), though shifted slightly in energy due to charging, confirmed no measurable sodium in the nearsurface region. This result confirms EDS and WDS results that suggest that the electron beam drives sodium ions out of the analysis region. The high boron-to-oxygen ratio points to oxygen loss by the crystal beyond that caused by vacuum dehydration. 


\section{References}

[1] D. E, Garrett, Borates: Handbook of Deposits, Processing, Properties, and Use (Academic Press, San Diego, CA, 1998)

[2] E. P. Vicenzi, D. C. Meier, and J. Davis, "Challenges involved in microanalysis of hydrated Naborate: Efforts to study a seemingly simple material," AMAS X, Adelaide, Australia, 11-13 February 2009.

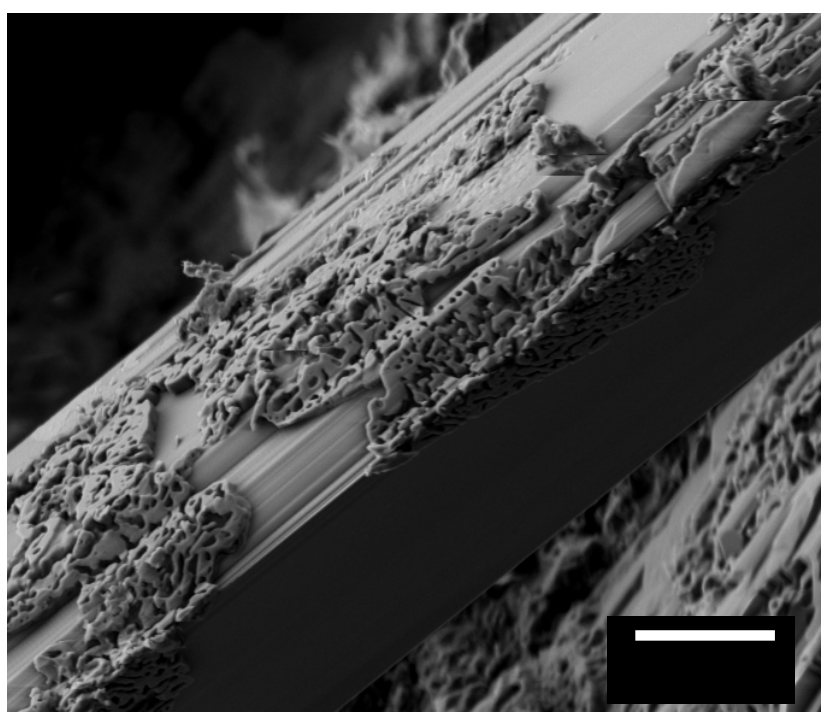

FIG 1. VP-SEM image of an as-received kernite crystal incompletely coated with an apparently amorphous submicrometer thick film. (5 kV, $\left.\mathrm{P}_{\mathrm{H}_{2} \mathrm{O}}=1.1 \times 10^{2} \mathrm{~Pa}\right)$.

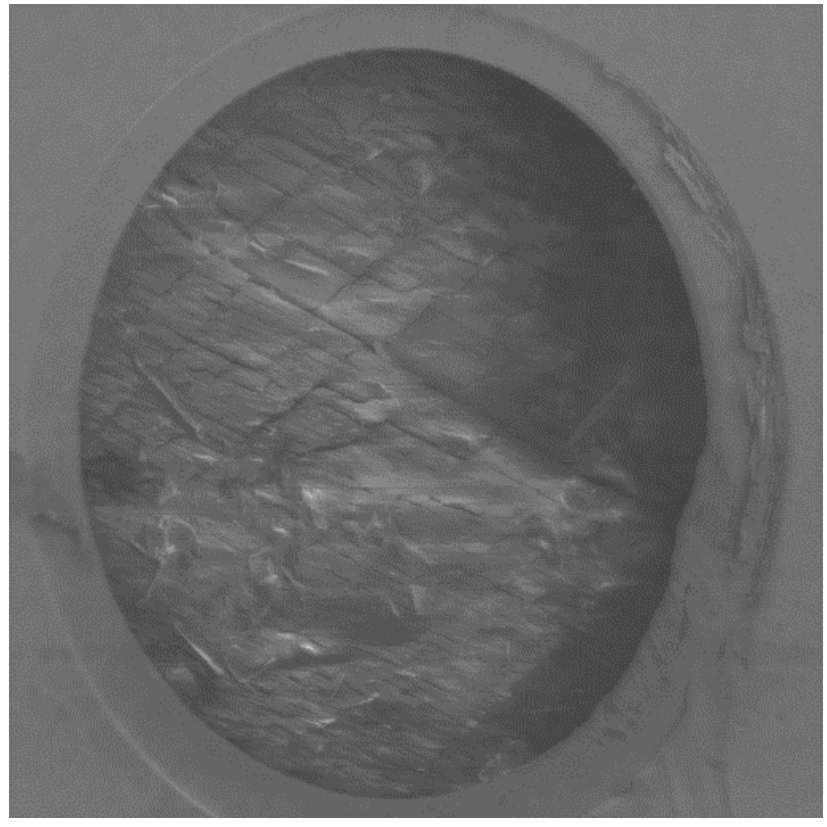

FIG 3. SEM image of kernite as viewed in UHV through a $300 \mu \mathrm{m}$ copper aperture $(430 \mathrm{X})$.

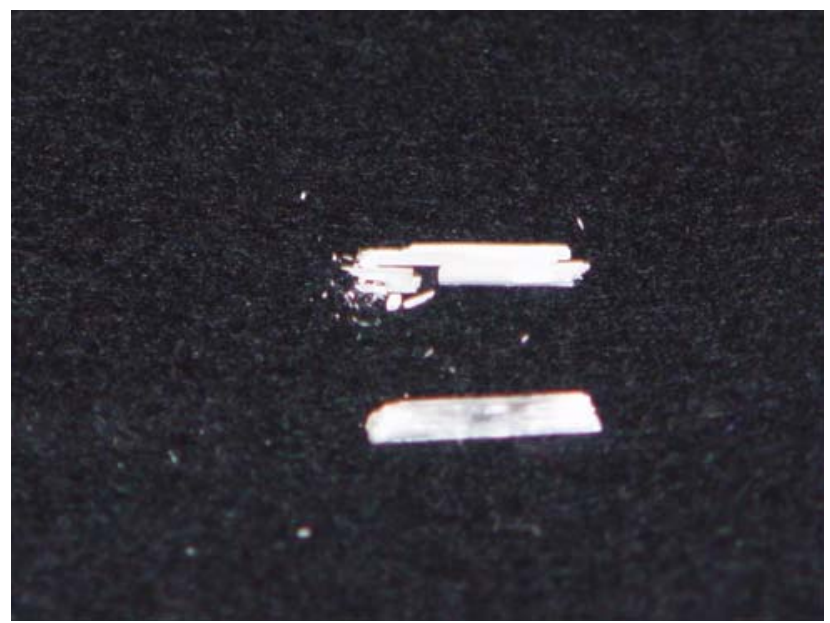

FIG 2. Photograph of kernite before (intact, bottom) and after (crumbling, top) vacuum dehydration.

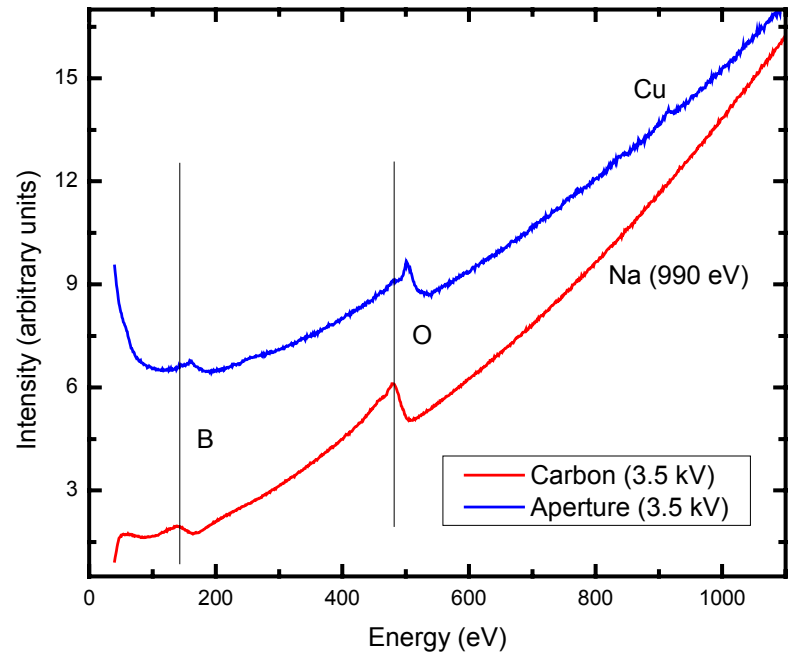

FIG 4. Auger electron spectra of kernite both under aperture (blue) and under carbon coating (red). Vertical lines show the energy offset due to specimen charging differences between methods. The low-energy intensity loss in the carbon-coated specimen indicates more significant charging effects. 